\title{
Making citizen science count: Best practices and challenges of citizen science projects on plastics in aquatic environments
}

\author{
Liselotte Rambonnet $^{\mathrm{a}}$, Suzanne C. Vink ${ }^{\mathrm{a}}$, Anne M. Land-Zandstra ${ }^{\mathrm{a}}$, Thijs Bosker ${ }^{\mathrm{b}, \mathrm{c}, *}$ \\ ${ }^{a}$ Science Communication and Society, Leiden University, P.O. Box 9505, 2300 RA Leiden, the Netherlands \\ ${ }^{\mathrm{b}}$ Leiden University College, Leiden University, P.O. Box 13228, 2501 EE The Hague, the Netherlands \\ ${ }^{\mathrm{c}}$ Institute of Environmental Sciences, Leiden University, P.O. Box 9518, 2300 RA Leiden, the Netherlands
}

\section{A R T I C L E I N F O}

\section{Keywords:}

Citizen science

Microplastics

Macroplastics

Global

Plastic pollution

\begin{abstract}
A B S T R A C T
There is considerable scientific and societal concern about plastic pollution, which has resulted in citizen science projects to study the scale of the issue. Citizen science is a cost-effective way to gather data over a large geographical range while simultaneously raising public awareness on the problem. Because the experiences of researchers involved in these projects are not yet adequately covered, this paper presents the findings from ten semi-structured qualitative interviews with researchers leading a citizen science project on micro- or macroplastics. Our results show it is important to specify the goal(s) of the project and that expertise on communication and data science is needed. Furthermore, simple protocols, quality control, and engagement with volunteers and the public are key elements for successful projects. From these results, a framework with recommendations was drafted, which can be used by anyone who wants to develop or improve citizen science projects.
\end{abstract}

\section{Introduction}

A significant portion of global plastic production is estimated to end up on the ocean surface, beaches, and the seafloor, thereby polluting our aquatic environments (Burns and Boxall, 2018; Horton et al., 2017; Jambeck et al., 2015). Research on macroplastics ( $>5 \mathrm{~mm}$ ) has demonstrated adverse effects on organisms, for example entanglement in ghost-nets and accumulation of plastics in the stomachs of organisms (Gall and Thompson, 2015; Machovsky-Capuska et al., 2019; Moore et al., 2009). Adverse impacts of microplastics $(<5 \mathrm{~mm})$ are less wellunderstood. However, because of their small size they can be ingested by various organisms (Gall and Thompson, 2015; Nelms et al., 2017; Rochman et al., 2015). As a result, there is a considerable scientific and societal concern about plastic pollution in the environment.

In order to examine the extent of the problem, extensive data collection with large geographical coverage is needed. To achieve this, the public is increasingly being involved in different phases of the scientific process, often during data collection or data analysis (Bosker et al., 2017; Hidalgo-Ruz et al., 2018; Nelms et al., 2017; Rech et al., 2015; Syakti et al., 2017). This type of public participation in the research process is often called citizen science (Bonney et al., 2009). Engaging with citizen scientists can extend coverage and increase sampling power without giving in on the data quality (Rech et al., 2015; van der
Velde et al., 2017). This saves researchers time and money (Kobori et al., 2016; van der Velde et al., 2017). In addition, engaging people in research and spreading scientific knowledge may increase awareness of environmental problems and can thereby result in better environmental and societal outcomes (Dickinson et al., 2010; McKinley et al., 2017). Both the researchers and the volunteers can benefit and learn from the citizen science experience (Dickinson and Bonney, 2012; Eastman et al., 2014).

The number of citizen science studies on plastics, both in marine and riverine ecosystems, has increased during the past few decades (Bergmann et al., 2017; Bosker et al., 2017; Hidalgo-Ruz et al., 2012; Nelms et al., 2017; Syakti et al., 2017; Zettler et al., 2017). Some of these projects have led to publications in peer-reviewed journals, but many more projects have used other forms of communication to report the results, such as reports or websites (Follett and Strezov, 2015). Most citizen science projects to date have focused on macroplastics, as these are more easily observed and sampled by volunteers in comparison to microplastics (Syberg et al., 2017; Zettler et al., 2017). Because plastic studies often focus on either macroplastics or microplastics, their approaches differ. For microplastics, some projects involve water sampling, where the volunteers use a bottle (Barrows et al., 2018) or a net (Davis and Murphy, 2015; Gewert et al., 2017), and others let volunteers do beach monitoring (Hidalgo-Ruz and Thiel, 2013; Lots et al.,

\footnotetext{
* Corresponding author at: Leiden University College, Leiden University, P.O. Box 13228, 2501 EE, The Hague, the Netherlands.

E-mail addresses: liselotte@rambonnet.com (L. Rambonnet), a.m.land@biology.leidenuniv.nl (A.M. Land-Zandstra), t.bosker@luc.leidenuniv.nl (T. Bosker).
} 
2017). In contrast, most citizen science projects on macroplastics consist of beach monitoring where participants count and report the types of plastic products they find (Nelms et al., 2017; Rech et al., 2015; Syakti et al., 2017).

Given the growing number of citizen science projects on plastic pollution, a trend which is likely to continue given the concern about the issue, it is important to evaluate their challenges, best practices, and recommendations to optimize both current and future projects. As citizen science in plastics research is a relatively young field, review papers are still limited (Hidalgo-Ruz and Thiel, 2017; Syberg et al., 2017; Zettler et al., 2017). For citizen science in general, the few reviews and guidelines that are available focus mostly on the volunteers' experiences and motivation. Only some studies have focused on the perspective of the researchers involved in citizen science projects through interviews (Cigliano et al., 2015; Golumbic et al., 2017; Roy et al., 2012). The lessons learnt by the coordinating researchers of citizen projects on plastics are not yet adequately covered. Therefore, the aim of this study was to explore best practices and challenges for citizen science projects on plastics in aquatic environments according to project researchers. Ten in-depth interviews were conducted with researchers from citizen science projects on micro- and macroplastics. The interview data was analysed to examine how researchers experience citizen science, what motivates them to conduct these citizen science studies, what benefits they gain and what challenges they face.

\section{Methods}

\subsection{Participants}

Ten citizen science projects on plastics, of which five focused on microplastics and five on macroplastics were selected (Table 1). The selection criteria were that 1) the aim of the project was to share the data with the scientific community, 2) the data collection started at least one year ago and 3) the approach varied between the projects as much as possible. This resulted in projects based in different parts of the world, with various approaches (Table 1; Supplementary information 1). Project coordinators were approached by email with an interview request and in case the project coordinator was not a scientist, the lead scientist of the project was asked. To ensure the privacy of participants, instead of their names, abbreviations of the corresponding projects were used in this paper.

\subsection{Interviews}

The interviews were conducted through phone or Skype, which is a viable alternative for in-person, face-to-face interviews (Iacono et al., 2016). The interviews were conducted in October and November 2018 and lasted approximately $45 \mathrm{~min}$ each. The interviews were semi- structured, using a pre-determined set of open-ended questions to structure the conversation and leaving sufficient room for follow-up questions depending on the answers (Jensen and Laurie, 2016). The questions focused on scientists' reasons for conducting a citizen science project, the challenges they encountered during the project, what went well, and the recommendations they have for other scientists.

Questions were developed based on existing frameworks and models for citizen science. In general, four main phases can be defined for a citizen science project: project design, data collection, data analysis, and outcome (Dickinson and Bonney, 2012; Tweddle et al., 2012). Briefly, the project design can include actions that mainly happen before the first data sampling by the volunteers. For example, defining research questions, setting goals, developing methods, and recruiting volunteers. During the data collection the volunteers will sample and record the data. In the data analysis phase, the researchers will examine the data. Throughout the outcome phase, the results are shared. The questions were covering these four main themes or phases (project design, data collection, data analysis and outcome) and the motivation of the researchers to conduct citizen science research (see Supplementary information 2).

\subsection{Data analysis}

The interviews were recorded with permission and transcribed to text using Express Scribe (version 7.01). These transcriptions were manually coded according to the principles of thematic analysis (Braun and Clarke, 2006) which means emerging themes from the data were identified. For the coding the qualitative analysis software MAXQDA Analytics Pro 2018 (Release 18.1.1) was used. The unit of analysis was either a sentence segment, a full sentence, or multiple consecutive sentences. The themes and their descriptions were combined into a code book (see Supplementary information 3 ). To check the reliability of the codes and themes, an independent second reader coded $10 \%$ of all the coded segments. The percentage of agreement between the first and second coder was $85 \%$.

\section{Results and discussion}

In this section the themes are presented that emerged from the analysis. Four of the themes correspond to the four phases of citizen science projects: project design, data collection, data analysis and outcome. Two themes were added that are relevant to every phase: interaction and motivation. Within each theme several subthemes are discussed. The quotes presented to support the results represent the most common view or clearest examples. We combine the results that we found in the current study with existing literature in the field of citizen science to draw up advice for citizen science projects involving plastic pollution research.

Table 1

Details of the citizen science projects included in the current project, including plastic type, project name, abbreviation used in remainder of paper, sampling approach and start date.

\begin{tabular}{|c|c|c|c|c|c|}
\hline Plastic type & Project name (location) & Abbrev. & Range $^{a}$ & Approach & Start date \\
\hline \multirow[t]{5}{*}{ Micro } & A Rocha (UK) & $\mathrm{AR}$ & International & Beach sediment sampling & 2017 \\
\hline & Adventure Scientists (USA) & AS & International & Water grab sampling & 2013 \\
\hline & Florida Microplastic Awareness Project (USA) & FMAP & Regional & Coastal water sampling and filtering & 2015 \\
\hline & Ucluelet Aquarium (Canada) & UA & Regional & Beach sediment sampling & 2017 \\
\hline & 5 Gyres (USA) & $5 \mathrm{G}$ & International & Filtering plastics using trawls & 2014 \\
\hline \multirow[t]{5}{*}{ Macro } & Cientificos de la Basura (Chile) & $\mathrm{CB}$ & National & Standardized beach litter sampling & 2007 \\
\hline & Makroplastik Nordsee (Germany) ${ }^{\mathrm{b}}$ & $\mathrm{MN}$ & International & Wooden drifters & 2016 \\
\hline & The Plastic Tide $(\mathrm{UK})^{\mathrm{c}}$ & PT & International & Tagging litter from photos & 2017 \\
\hline & Beachwatch \& Great British Beach Clean (UK) & MCS & National & Beach clean-ups & 1994 \\
\hline & Schone Rivieren (Netherlands) & SR & National & River bank clean-ups and monitoring & 2016 \\
\hline
\end{tabular}

\footnotetext{
a The range indicates the geographical range where citizen science can participate.

b Official project title is Macroplastics Pollution in the Southern North Sea - Sources, Pathways, and Abatement Strategies.

c The Plastic Tide ended in 2019 and their work continues in Ellipsis Environmental.
} 


\subsection{Project design}

The participants in this study highlighted the importance of defining a dual goal within their projects: engaging the public as well as furthering research about plastic pollution. For example, FMAP stated that "I am one person, and this is a big state, and I knew that there was no way that I could go around and collect samples and data". In addition, it helps to connect people to the problem: "It is not until they [volunteers] get on the beach and identify and record it [itter] that they really acknowledge it" (MCS), and "having citizen scientists really helps them to connect to an important issue in their community" (UA).

Even though a dual approach is often highlighted as a key advantage of citizen science, review articles found that most citizen science projects do not use the outcomes for scientific research (Follett and Strezov, 2015; Kullenberg and Kasperowski, 2016). Two of our interviewees who were involved in microplastics projects also highlighted this as being a challenge, stating, for example: "If you want publishable data, for microplastics I'm not really sure that citizen science is the way to go" (FMAP). This indicates that it is important to clarify the goals of the citizen science projects during the first phase of the project.

Advice 1. Specify the goal of the project: is the emphasis on robust and reliable science, engaging the public or both.

Researchers are becoming more aware that citizen science is not only about science but also about society and politics (Crain et al., 2014; Dickinson et al., 2010). Interestingly, informing policy was only mentioned by one project as an explicit goal: "One of the goals of the project is also to make the monitoring obligatory for the government. We want the monitoring to be embedded into regulation. So that the data that is collected is actually used to formulate policies by the government and act upon plastic pollution" (SR).

Although influencing policies was not mentioned as an explicit goal for the other projects, results were shared with or used by policymakers in some cases. "All of our data is often used as evidence, to support a policy that would limit plastic pollution from entering the ocean, or bay" (5G). Interviewees recommended to think about how your data can potentially influence policies; "It [standard sampling form] helped us to look at specific litter items to inform policy. I think it is important to kind of think ahead of what you might want to do in the future and get the required data... I think it is been really great that we have some litter items that go back for such a long time. In particular litter items that really helped us to inform policies" (MCS). A previous study by Zettler has shown that data on plastic clean-ups is an effective tool to influence policies (Zettler et al., 2017). If influencing policies is one of the goals, it is recommended to engage with an expert or organisation focusing on governance and legislative issues during the design phase of the project, to increase the chance that it can positively impact policy (Cigliano et al., 2015; Hecker et al., 2018)

Advice 2. Consider whether one of the outcomes of the project is to inform policymakers, and if so, include experts on governance and legislative issues in the design phase.

Because citizen science projects are not only about science but also about society and politics, including multiple disciplines in a project team is important in order to handle all the aspects of a citizen science project (McKinley et al., 2017). For example, if a (sub)goal of the project is to understand how to change human behaviour, or affect policies regarding marine debris, it could be beneficial to involve social psychologists (Dickinson et al., 2010; Vegter et al., 2014). "Collaboration is absolutely fundamental because everybody brings something to the project. For example, we have been collaborating with statisticians and educators" (CB).
There are two key fields of expertise that several interviewees recommend to include in any citizen science team: communication and data science. Three researchers mentioned the importance of having a team member who is available for the communication with volunteers. Either in the field, to "oversee what they are doing... and be available to answer their questions" (FMAP), or in the office, because "regardless of how brilliant your website has been and as communicative as it could be, when it comes to citizen science...you always get people who just want to speak to someone on the phone or by email" (MCS). One project also mentioned their need for someone who communicates about the project in general: "I would really like...if I could have a science communications officer. I could fill their time just communicating about plastics" (AR). These outcomes are in line with previous research, which highlighted the importance of having communication experts in the project teams (Cigliano et al., 2015; Tweddle et al., 2012).

Regarding data science, four researchers mentioned the need for expertise or support in the team on managing the data and data analysis. For example: "I think [I missed] more focus on data analysis and data management. It is also always a plus" (MCS). These suggestions highlight the need for an interdisciplinary team. In addition to this, developing a plan on the communication is highly recommended when trying to build a community of volunteers to participate and stay involved (Luna et al., 2018). Also developing a data management plan for a citizen science projects is recommended in literature and several guides are available, for example on dataONE.org and citizenscience.org (McKinley et al., 2017; Schade and Tsinaraki, 2016).

Advice 3. Depending on the goal of the project, set-up an interdisciplinary team of collaborators who can give advice on different aspects of the project during the design phase.

Advice 4. Include a communication expert and data expert in the team. Regardless, make sure to have a well-developed communication and data plan.

A final key consideration during the project design is quality control, an important topic in citizen science projects in general (Tulloch et al., 2013; Zettler et al., 2017). A challenge that four of the projects encountered was the amount of detail a volunteer can record. "The biggest challenge is probably balancing scientific detail with the average ability of a citizen science tagger. That is probably the biggest trade off" (PT). One researcher stressed that knowing the background of the volunteers is helpful to determine this: "We know our community that we are working with. So this helps us to be able to understand what they are able to do and what they couldn't, and what they'd be willing to do" (5G). Several studies have highlighted that there has been scepticism and mistrust about the quality of the data collected in citizen science projects (Bahls, 2014). However, citizen science is now appearing increasingly in peer reviewed journals (Follett and Strezov, 2015).

Therefore, if collecting high-quality data is the main goal, to publish or to influence legislation, developing very clear, simple protocols is important (Besley et al., 2017; Parsons et al., 2011; Zettler et al., 2017). "The most important part I think is to have it really simple ... and repeatable, so anyone else could do it and contribute to our data" (UA).

Half of the interviewees talked about the importance of doing a pilot study before data collection begins. Two of them, both microplastics researchers, strongly advocate for trying the protocols yourself. " $D o$ it yourself. ...Go out and try it in different conditions. The way you have your data sheet set-up: is it intuitive? Does it make sense?" (AS). Testing the protocol is also recommended by Tweddle et al. (2012). Self-testing the protocols in the field or together with volunteers, helped researchers to see whether the instructions are intuitive and how people are using them. 
Advice 5. Develop a sampling protocol which meets the goals of the project and the background of the volunteers and test these protocols in a pilot study.

\subsection{Data collection}

No major problems were mentioned by researchers regarding volunteers collecting the data. "I've seen how people collect and [...] the actual collection of the plastics has been uniform throughout the whole time we've sampled. Which is important for collecting consistent data" (UA).

Although most projects adopted a sampling design that was as basic as possible, sometimes problems still arose, especially in the projects focusing on microplastics. One of these issues was volunteers making mistakes during data collection: "You would be surprised people can mess up dipping a bottle of water into a body of water, but the idea is very easy, right? The thing is, people get excited when they are in the field, so they would not always keep the bottle underwater" (AS). In addition, some of the researchers encountered issues with retention, as sampling in the field (especially for the microplastics projects) can be perceived as dull or boring by the participants: "It's long and it's hot. Even our volunteers in Portugal say: we know it is really important to be on the beach, but it takes a lot of effort" (AR). According to researchers it is therefore important to keep in mind the concentration span and thus the sampling duration. To ensure high quality of the data, and to prevent volunteers from dropping out, it is advised that complex tasks can be broken down into activities that take less time and effort (Eveleigh et al., 2014). Naturally, demographics of the volunteers should be kept in mind regarding this issue. For instance, school children have a shorter attention span than adults (Boyden and Ennew, 1997) and sampling duration should be adjusted accordingly.

Advice 6. Keep attention spans of volunteers in mind when determining sampling duration.

Some researchers encountered issues with receiving the collected data from the volunteers. Several times this was because of the tool which volunteers had to use to enter their data: "Initially we started with just paper data sheets ...but it is very labour intensive, and you have to read people's writing, the papers got wet or whatever. So that was a challenge" (AS). Other times there were difficulties with receiving the data from the volunteers, after they collected it. "We actually moved from paper form to a website. That helped greatly with the process" (MCS). Though new technologies could in the past create barriers for those avoiding or lacking it (Ess and Sudweeks, 2001), digital tools are now used increasingly in citizen science (Bonney et al., 2014; Silvertown, 2009). They can contribute to a more efficient way of entering data in the field, and advance research due to increased value of datasets (Newman et al., 2012). Regarding volunteers, user friendliness, ease of use and accessibility should be kept in mind when designing a tool for data entry (Sturm et al., 2018), as well as the technological skills of your participants (Newman et al., 2012). Entering data online was mentioned by four researchers as a helpful solution based on their experiences with online tools like Zooniverse and BeachExplorer.

Advice 7. Use digital tools for recording and submitting data to increase efficiency and value of datasets.

\subsection{Data analysis}

Quality control was mentioned by eight projects as an important factor during data analysis, especially when the goal is to publish the data in a peer-reviewed journal. To that end, most projects conduct quality control checks to ensure that data meets quality standards: " $I$ wanted to feel really confident and stand behind it as a scientist. So, we did a bunch of different quality assurance and quality control methods that we built into the protocols, both in the field site and also in the lab" (AS). Consistency in analysis methods was mentioned to assure quality control during data analysis. "We stick to the same instructions, whoever does the analysis, which changes over the years" (MCS). Both building in quality assurance measures in the sampling design and protocols, and some quality control methods are needed during the analysis of the data (Kosmala et al., 2016).

Advice 8. Include quality assurance and quality control in protocols.

Researchers talked about the amount of data that has to be analysed: "Working with mass data like that and making sure that it actually made sense" (AS) was challenging, as well as focusing on certain questions: "It is always difficult to really narrow it down to something and not get lost in detail" (MN). A researcher noted that having expertise on (big) data management "will even become more important" (MN). As the popularity of citizen science projects is increasing and online tools are being used more often, the amount of data is also growing rapidly (Kullenberg and Kasperowski, 2016). To get a grip on these large datasets during the analysis, having expertise on data management is recommended by our interviewees and in literature (Hochachka et al., 2012). As online tools and mobile apps are becoming more common in data collection, it is important to ensure data collected via offline and online methods are still comparable (Dickinson and Bonney, 2012; Zettler et al., 2017). With more and more projects having digital datasets it becomes easier to compare and integrate data between projects. Internationally, researchers are working on a model for this interoperability (Göbel et al., 2017) Guidelines are being developed to report data and metadata (when, where, how and by whom the data was collected) so that data can be shared and compared across projects leading to more impactful outcomes (Kosmala et al., 2016; Roy et al., 2012; Wang et al., 2015).

Advice 9. If comparing and combining with other (citizen science) data sets is important, make sure to collect data and metadata according to existing protocols.

\subsection{Outcome}

In the outcome phase, results of the citizen science project should be communicated not just with the scientific community, but with other stakeholders as well. Interviewees recognised the importance of sharing the results of the project with volunteers and the public. "The key people are the volunteers. If we want to share information, they need to be the first ones. This was not something that we had planned for in the beginning. But we realized it is an important aspect to get back to them" (CB).

Sharing results was undertaken in various manners, including reports, social media, press releases, news articles, presentations, and weblogs. The chosen manner of informing the volunteers and other audiences about the results, depends on the target audience and was sometimes a challenge: "So how do we effectively transcribe our data into something the general public can digest and actually effectively understand. I think that is a growing topic" (UA). As was also mentioned when discussing the design phase, collaborating with (science) communication experts can resolve some of these challenges.

Citizen science can have an important role in delivery and understanding of future marine policy, if their outputs have the right quality (Hyder et al., 2015). Communicating with different stakeholders the project can have impact on different levels of policy making, inform (local) government and change legislation. Data is used, for example, "as evidence, to support a policy that would limit plastic pollution from entering the ocean, or bay" (5G), or "it can help with campaigns to reduce 
certain types of litter" (MCS). In some cases, volunteers can be instrumental in dissemination of the outcomes of the project towards society, for example "for sponsorship or for talking to their community" (AS). Engagement between scientists, policy makers and citizen scientists is thus necessary to make sure that the potential benefits of citizen science in supporting policy are realized (Teacher et al., 2013). Citizen science encourages engagement between members of the public and decision makers (Wehn and Evers, 2014).

Volunteers can use their experiences during a project to inform others in society, for example "for sponsorship or for talking to their community" (AS). Also, some projects have an impact on different levels of policy making, to inform (local) governments and to change legislation. Data is used, for example, "as evidence, to support a policy that would limit plastic pollution from entering the ocean, or bay" (5G), or "it can help with campaigns to reduce certain types of litter" (MCS).

Advice 10. When one of the goals of the project is to impact policy or society, make sure communication about project outcomes is geared towards different stakeholders, such as the general public and policymakers. Volunteers can play an important role in dissemination towards these stakeholders.

\subsection{Continuous interaction}

In the previous section we discussed the importance of communicating the outcomes of the project with different stakeholders. However, during the project, interaction with the volunteers is important as well: "I think if scientists are planning a citizen science project, they should incorporate an engagement element, an outreach element with the citizen science community and beyond as well." (PT). Interaction with volunteers in terms of keeping them updated about project progress, providing ways to meet or hear about other volunteers and asking them feedback on how to improve the project can create a sense of community and are important for retention of participants (Dickinson and Bonney, 2012; Eveleigh et al., 2014), and sustainability and effectiveness of the project overall (Danielsen et al., 2005). Especially with a topic such as plastic waste, which triggers activist motivations in volunteers, participants want to know that their efforts are actually contributing towards a solution for the waste problem (Land-Zandstra and van Oostrum, 2019). Keeping them "in the loop" throughout the project will help retain them (de Vries et al., 2019), since dropping out has been associated with lack of information about the project (Eveleigh et al., 2014). Another important aspect of interaction with volunteers is acknowledging their contributions: "so they can re-share project results and details to highlight what they are doing. This way, they can get validation that they are involved in the program" (5G). This can be done by addressing their role in the project in all communication within the project as well as to external stakeholders. In addition, acknowledging citizen scientists in scientific publications, either in the acknowledgements or as (collective) author is more and more common as well (Alender, 2016; Haywood, 2016).

Advice 11. Engaging with and acknowledging volunteers helps to keep them motivated and retain them.

\subsection{Researcher motivation}

In most cases, personal motivation was the key reason for scientists to start a citizen science project on plastics. Their background, passions, faith, or a specific event motivated them to not only study plastics, but also engage the public to spread awareness: "And that place is magical for me, and seeing it change so much. It really has had an impact on me and has made me motivated to change what I do, personally, as well as I encourage others to do the same" (FMAP). The most mentioned motivating factor during the project, was noticing the impact the project has on volunteers and society: "Seeing how many people are already thinking about this or how many people I can reach with this project, this is something I could have never dreamed of beforehand but I'm really happy that I had the opportunity to [experience this]" (MN). Another researcher hopes for a time in which investigating and teaching about marine litter is not necessary anymore. "I sometimes think...how unfortunate we have this programme because I would rather bring marine biology to the kids...But instead I teach them about marine litter, this is painful sometimes" (CB).

Wanting to solve the problem is mentioned in literature as an important reason to start a citizen science project (Geoghegan et al., 2016). Our results show that motivational factors during the project differ between researchers, but that noticing the impact the project has on the public is considered motivating by a lot of researchers. Educating people, raising awareness and engaging people in the issue are often found as motivational factors in literature (Geoghegan et al., 2016).

Only the slow pace and the unexpected extra efforts were considered demotivating or a personal challenge for some researchers: "It is always waiting for feedback, some challenges you encounter or did not think about" $(M N)$. That citizen science is time consuming is also known from other studies (Danielsen et al., 2005; Geoghegan et al., 2016; Hecker et al., 2018).

Advice 12. Scientists are often motivated to citizen science because they want to make a change in the world. However, realistic expectations need to be set in the project. For example, data collection can take considerable amounts of time, and project management can be a time sink.

\subsection{Framework}

As the number of citizen science projects is increasing, also the lessons that can be learned from these projects are (Silvertown, 2009), resulting in guidelines which guide new projects (Roy et al., 2012; Tweddle et al., 2012). In order to make these guidelines suitable for the field of plastic pollution research, we developed a framework with practical advice for the design and running of citizen science projects on micro- and macroplastics (Fig. 1). The framework was created based on the four different themes from literature and the results from the interviews. The four phases of design, data collection, data analysis and outcome succeed one another, but often a project is developed according to an iterative process, going back and forth through different stages. Two central themes are applicable to every phase: motivation of the researcher(s) and interaction with the volunteers.

\section{Declaration of Competing Interest}

The authors declare that they have no competing interests.

\section{Acknowledgements}

We would like to thank the researchers who participated in this study and shared their experiences with one of the following projects: Adventure Scientists, A Rocha, Cientificos de la Basura, Florida Microplastic Awareness Project, Marine Conservation Society, Makroplastik Nordsee, Schone Rivieren, The Plastic Tide, 5 Gyres, and Ucluelet Aquarium. 


\section{Design}

1. Specify goal(s) of project

2. When informing policy makers is one of goals or outcomes, involve them from start

3. Include other disciplines in team or collaborations

4. Include communication expert and data expert and develop communication and data plan

5. Adapt your sampling protocol to project goals and background of volunteers

\section{Data Collection}

6. Be aware of attention span of volunteers during sampling

7. Use digital tools for recording and submitting data

$$
\text { Data Analysis }
$$

8. Include quality assurance and quality control in protocols

9. Involve data experts in the team and keep track of metadata

10. Share results with different stakeholders

Fig. 1. Framework with recommendations for improving or developing a citizen science project.
Interaction

11. Engage with and acknowledge volunteers to keep them motivated and involved

\section{Motivation}

12. Be aware of time and effort needed for citizen science project aspects like communication and project management

\section{Appendix A. Supplementary data}

Supplementary data to this article can be found online at https:// doi.org/10.1016/j.marpolbul.2019.05.056.

\section{References}

Alender, B., 2016. Understanding volunteer motivations to participate in citizen science projects: a deeper look at water quality monitoring. J. Sci. Commun. 15. https://doi. org/10.22323/2.15030204.

Bahls, L.L., 2014. New diatoms from the American West-a tribute to citizen science. Proc. Acad. Nat. Sci. Philadelphia 163, 61-84. https://doi.org/10.1635/053.163. 0109.

Barrows, A.P.W., Cathey, S.E., Petersen, C.W., 2018. Marine environment microfiber contamination: global patterns and the diversity of microparticle origins. Environ. Pollut. 237, 275-284. https://doi.org/10.1016/j.envpol.2018.02.062.

Bergmann, M., Lutz, B., Tekman, M.B., Gutow, L., 2017. Citizen scientists reveal: marine litter pollutes Arctic beaches and affects wild life. Mar. Pollut. Bull. 125, 535-540. https://doi.org/10.1016/j.marpolbul.2017.09.055.

Besley, A., Vijver, M.G., Behrens, P., Bosker, T., 2017. A standardized method for sampling and extraction methods for quantifying microplastics in beach sand. Mar. Pollut. Bull. 114, 77-83. https://doi.org/10.1016/j.marpolbul.2016.08.055.

Bonney, R., Cooper, C.B., Dickinson, J., Kelling, S., Phillips, T., Rosenberg, K.V., Shirk, J., 2009. Citizen science: a developing tool for expanding science knowledge and scientific literacy. Bioscience 59, 977-984. https://doi.org/10.1525/bio.2009.59.11.9.

Bonney, R., Shirk, J.L., Phillips, T.B., Wiggins, A., Ballard, H.L., Miller-Rushing, A.J., Parrish, J.K., 2014. Citizen science: next steps for citizen science. Science 343, 1436-1437. https://doi.org/10.1126/science.1251554.

Bosker, T., Behrens, P., Vijver, M.G., 2017. Determining global distribution of microplastics by combining citizen science and in-depth case studies. Integr. Environ. Assess. Manag. 13, 536-541. https://doi.org/10.1002/ieam.1908.

Boyden, J., Ennew, J., 1997. Children in Focus a Manual.

Braun, V., Clarke, V., 2006. Using thematic analysis in psychology. Qual. Res. Psychol. https://doi.org/10.1191/1478088706qp063oa.

Burns, E.E., Boxall, A.B.A., 2018. Microplastics in the aquatic environment: evidence for or against adverse impacts and major knowledge gaps. Environ. Toxicol. Chem. 37, 2776-2796. https://doi.org/10.1002/etc. 4268.

Cigliano, J.A., Favaro, B., Oester, S., Parsons, E.C.M., 2015. Making marine science matter - a special issue highlighting the third International Marine Conservation Congress. Ocean Coast. Manag. 115, 1-3. https://doi.org/10.1016/j.ocecoaman.2015.09.008.

Crain, R., Cooper, C., Dickinson, J.L., 2014. Citizen science: a tool for integrating studies of human and natural systems. Annu. Rev. Environ. Resour. 39, 641-665. https://doi. org/10.1146/annurev-environ-030713-154609.

Danielsen, F., Burgess, N.D., Balmford, A., 2005. Monitoring matters: examining the potential of locally-based approaches. Biodivers. Conserv. 14, 2507-2542. https:// doi.org/10.1007/s10531-005-8375-0.

Davis, W., Murphy, A.G., 2015. Plastic in surface waters of the Inside Passage and beaches of the Salish Sea in Washington State. Mar. Pollut. Bull. 97, 169-177. https://doi.org/ 10.1016/j.marpolbul.2015.06.019.

de Vries, M., Land-Zandstra, A., Smeets, I., 2019. Citizen scientists' preferences for communication of scientific output: a literature review. Citiz. Sci. Theory Pract. 4, 1-13. https://doi.org/10.5334/cstp.136.
Dickinson, J.L., Bonney, R., 2012. Citizen Science, 1st ed. Cornell University Press. Dickinson, J.L., Zuckerberg, B., Bonter, D.N., 2010. Citizen science as an ecological research tool: challenges and benefits. Annu. Rev. Ecol. Evol. Syst. 41, 149-172. https://doi.org/10.1146/annurev-ecolsys-102209-144636.

Eastman, L., Hidalgo-Ruz, V., Macaya, V., Nuñez, P., Thiel, M., 2014. The potential for young citizen scientist projects: a case study of Chilean schoolchildren collecting data on marine litter. Rev. Gestão Costeira Integr. 14, 569-579. https://doi.org/10.5894/ rgci507.

Ess, C., Sudweeks, F., 2001. On the edge - cultural barriers and catalysts to IT diffusion among remote and marginalized communities. New Media Soc. 3, 259-269.

Eveleigh, A., Jennett, C., Blandford, A., Brohan, P., Cox, A.L., 2014. Designing for dabblers and deterring drop-outs in citizen science. In: Proceedings of the 32nd Annual ACM Conference on Human Factors in Computing Systems - CHI'14, https://doi.org/ 10.1145/2556288.2557262.

Follett, R., Strezov, V., 2015. An analysis of citizen science based research: usage and publication patterns. PLoS One 10. https://doi.org/10.1371/journal.pone.0143687.

Gall, S.C., Thompson, R.C., 2015. The impact of debris on marine life. Mar. Pollut. Bull. 92, 170-179. https://doi.org/10.1016/j.marpolbul.2014.12.041.

Geoghegan, H., Dyke, A., Pateman, R., West, S., Everett, G., 2016. Understanding Motivations for Citizen Science.

Gewert, B., Ogonowski, M., Barth, A., MacLeod, M., 2017. Abundance and composition of near surface microplastics and plastic debris in the Stockholm Archipelago, Baltic Sea. Mar. Pollut. Bull. 120, 292-302. https://doi.org/10.1016/j.marpolbul.2017.04. 062 .

Göbel, C., Martin, V.Y., Ramírez-Andreotta, M., 2017. Stakeholder Analysis: International Citizen Science Stakeholder Analysis on Data Interoperability. https://doi.org/10. 13140/RG.2.2.26124.92802.

Golumbic, Y.N., Orr, D., Baram-Tsabari, A., Fishbain, B., 2017. Between vision and reality: a case study of scientists' views on citizen science. Citiz. Sci. Theory Pract. 2, 1-13. https://doi.org/10.5334/cstp.53.

Haywood, B.K., 2016. Beyond data points and research contributions: the personal meaning and value associated with public participation in scientific research. Int. J. Sci. Educ. Part B Commun. Public Engagem. 6, 239-262. https://doi.org/10.1080/ 21548455.2015.1043659.

Hecker, S., Bonney, R., Haklay, M., Hölker, F., Hofer, H., Goebel, C., Gold, M., Makuch, Z., Ponti, M., Richter, A., Robinson, L., Iglesias, J.R., Owen, R., Peltola, T., Sforzi, A., Shirk, J., Vogel, J., Vohland, K., Witt, T., Bonn, A., 2018. Innovation in citizen science - perspectives on science-policy advances. Citiz. Sci. Theory Pract. 3, 1-14. https:// doi.org/10.5334/cstp.114.

Hidalgo-Ruz, V., Thiel, M., 2013. Distribution and abundance of small plastic debris on beaches in the SE Pacific (Chile): a study supported by a citizen science project. Mar. Environ. Res. 87-88, 12-18. https://doi.org/10.1016/j.marenvres.2013.02.015.

Hidalgo-Ruz, V., Thiel, M., 2017. The contribution of citizen scientists to the monitoring of marine litter. In: Marine Pollution Bulletin. Elsevier, pp. 429-447. https://doi.org/ 10.1016/j.marpolbul.2017.09.055

Hidalgo-Ruz, V., Gutow, L., Thompson, R.C., Thiel, M., 2012. Microplastics in the marine environment: a review of the methods used for identification and quantification. Environ. Sci. Technol. 46, 3060-3075. https://doi.org/10.1021/es2031505.

Hidalgo-Ruz, V., Honorato-Zimmer, D., Gatta-Rosemary, M., Nuñez, P., Hinojosa, I.A., Thiel, M., 2018. Spatio-temporal variation of anthropogenic marine debris on Chilean beaches. Mar. Pollut. Bull. 126, 516-524. https://doi.org/10.1016/j.marpolbul. 2017.11.014.

Hochachka, W.M., Fink, D., Hutchinson, R.A., Sheldon, D., Wong, W.K., Kelling, S., 2012. Data-intensive science applied to broad-scale citizen science. Trends Ecol. Evol. 27, 
130-137. https://doi.org/10.1016/j.tree.2011.11.006.

Horton, A.A., Walton, A., Spurgeon, D.J., Lahive, E., Svendsen, C., 2017. Microplastics in freshwater and terrestrial environments: evaluating the current understanding to identify the knowledge gaps and future research priorities. Sci. Total Environ. 586, 127-141. https://doi.org/10.1016/j.scitotenv.2017.01.190.

Hyder, K., Townhill, B., Anderson, L.G., Delany, J., Pinnegar, J.K., 2015. Can citizen science contribute to the evidence-base that underpins marine policy? Mar. Policy 59, 112-120. https://doi.org/10.1016/j.marpol.2015.04.022.

Iacono, V. Lo, Symonds, P., Brown, D.H.K., 2016. Skype as a tool for qualitative research interviews. Sociol. Res. Online 21, 1-15. https://doi.org/10.5153/sro.3952.

Jambeck, J.R., Geyer, R., Wilcox, C., Siegler, T.R., Perryman, M., Andrady, A., Narayan, R., Law, K.L., 2015. Plastic waste inputs from land into the ocean. Science 347, 768-771. https://doi.org/10.1126/science.1260352. (80-.).

Jensen, E., Laurie, C., 2016. Doing Real Research: A Practical Guide to Social Research. Sage.

Kobori, H., Dickinson, J.L., Washitani, I., Sakurai, R., Amano, T., Komatsu, N., Kitamura, W., Takagawa, S., Koyama, K., Ogawara, T., Miller-Rushing, A.J., 2016. Citizen science: a new approach to advance ecology, education, and conservation. Ecol. Res. 31, 1-19. https://doi.org/10.1007/s11284-015-1314-y.

Kosmala, M., Wiggins, A., Swanson, A., Simmons, B., 2016. Assessing data quality in citizen science. Front. Ecol. Environ. 14, 551-560. https://doi.org/10.1002/fee. 1436.

Kullenberg, C., Kasperowski, D., 2016. What is citizen science? - a scientometric metaanalysis. PLoS One 11, 1-16. https://doi.org/10.1371/journal.pone.0147152.

Land-Zandstra, A.M., van Oostrum, A., 2019, March. What are you doing with our data? Clean Rivers participants' preferences for feedback about project outcomes. Poster presented at the Citizen Science Association conference, Raleigh, NC.

Lots, F.A.E., Behrens, P., Vijver, M.G., Horton, A.A., Bosker, T., 2017. A large-scale investigation of microplastic contamination: abundance and characteristics of microplastics in European beach sediment. Mar. Pollut. Bull. 123, 219-226. https://doi. org/10.1016/j.marpolbul.2017.08.057.

Luna, S., Gold, M., Albert, A., Ceccaroni, L., Claramunt, B., Danylo, O., Haklay, M., Korrmann, R., Kyba, C., Piera, J., Radicchi, A., Schade, S., Sturm, U., 2018. Developing Mobile Applications for Environmental and Biodiversity Citizen Science: Considerations and Recommendations, Multimedia Tools and Applications for Environmental \& Biodiversity Informatics. Springer chhttps://doi.org/10.1007/9783-319-76445-0 2.

Machovsky-Capuska, G.E., Amiot, C., Denuncio, P., Grainger, R., Raubenheimer, D., 2019. A nutritional perspective on plastic ingestion in wildlife. Sci. Total Environ. 656, 789-796. https://doi.org/10.1016/j.scitotenv.2018.11.418.

McKinley, D.C., Miller-Rushing, A.J., Ballard, H.L., Bonney, R., Brown, H., Cook-Patton, S.C., Evans, D.M., French, R.A., Parrish, J.K., Phillips, T.B., Ryan, S.F., Shanley, L.A., Shirk, J.L., Stepenuck, K.F., Weltzin, J.F., Wiggins, A., Boyle, O.D., Briggs, R.D., Chapin, S.F., Hewitt, D.A., Preuss, P.W., Soukup, M.A., 2017. Citizen science can improve conservation science, natural resource management, and environmental protection. Biol. Conserv. 208, 15-28. https://doi.org/10.1016/j.biocon.2016.05 015.

Moore, E., Lyday, S., Roletto, J., Litle, K., Parrish, J.K., Nevins, H., Harvey, J., Mortenson, J., Greig, D., Piazza, M., Hermance, A., Lee, D., Adams, D., Allen, S., Kell, S., 2009. Entanglements of marine mammals and seabirds in central California and the northwest coast of the United States 2001-2005. Mar. Pollut. Bull. 58, 1045-1051. https:// doi.org/10.1016/j.marpolbul.2009.02.006.

Nelms, S.E., Coombes, C., Foster, L.C., Galloway, T.S., Godley, B.J., Lindeque, P.K., Witt, M.J., 2017. Marine anthropogenic litter on British beaches: a 10-year nationwide assessment using citizen science data. Sci. Total Environ. 579, 1399-1409. https:// doi.org/10.1016/j.scitotenv.2016.11.137.

Newman, G., Wiggins, A., Crall, A., Graham, E., Newman, S., Crowston, K., 2012. The future of citizen science: emerging technologies and shifting paradigms. Front. Ecol. Environ. 10, 298-304. https://doi.org/10.1890/110294.
Parsons, J., Lukyanenko, R., Wiersma, Y., 2011. Easier citizen science is better. Nature 471, 37. https://doi.org/10.1038/471037a.

Rech, S., Macaya-Caquilpán, V., Pantoja, J.F., Rivadeneira, M.M., Campodónico, C.K., Thiel, M., 2015. Sampling of riverine litter with citizen scientists - findings and recommendations. Environ. Monit. Assess. 187. https://doi.org/10.1007/s10661015-4473-y.

Rochman, C.M., Tahir, A., Williams, S.L., Baxa, D.V., Lam, R., Miller, J.T., Teh, F.C., Werorilangi, S., Teh, S.J., 2015. Anthropogenic debris in seafood: plastic debris and fibers from textiles in fish and bivalves sold for human consumption. Sci. Rep. https://doi.org/10.1038/srep14340.

Roy, H.E., Pocock, M.J.O., Preston, C.D., Roy, D.B., Savage, J., Tweddle, J.C., Robinson, L.D., 2012. Understanding Citizen Science and Environmental Monitoring. UK Environmental Observation Framework.

Schade, S., Tsinaraki, C., 2016. Survey report: data management in citizen science projects. JRC Technical Reports. https://doi.org/10.2788/539115.

Silvertown, J., 2009. A new dawn for citizen science. Trends Ecol. Evol. 24, 467-471. https://doi.org/10.1016/j.tree.2009.03.017.

Sturm, U., Schade, S., Ceccaroni, L., Gold, M., Kyba, C., Claramunt, B., Haklay, M., Kasperowski, D., Albert, A., Piera, J., Brier, J., Kullenberg, C., Luna, S., 2018. Defining principles for mobile apps and platforms development in citizen science. Research Ideas and Outcomes. https://doi.org/10.3897/rio.4.e23394.

Syakti, A.D., Bouhroum, R., Hidayati, N.V., Koenawan, C.J., Boulkamh, A., Sulistyo, I., Lebarillier, S., Akhlus, S., Doumenq, P., Wong-Wah-Chung, P., 2017. Beach macrolitter monitoring and floating microplastic in a coastal area of Indonesia. Mar. Pollut. Bull. 122, 217-225. https://doi.org/10.1016/j.marpolbul.2017.06.046.

Syberg, K., Nielsen, A., Khan, F.R., Banta, G.T., Palmqvist, A., Jepsen, P.M., 2017. Microplastic potentiates triclosan toxicity to the marine copepod Acartia tonsa (Dana). J. Toxicol. Environ. Heal. - Part A Curr. Issues 80, 1369-1371. https://doi. org/10.1080/15287394.2017.1385046.

Teacher, A.G.F., Griffiths, D.J., Hodgson, D.J., Inger, R., 2013. Smartphones in ecology and evolution: a guide for the apprehensive. Ecol. Evol. 3, 5268-5278. https://doi. org/10.1002/ece3.888

Tulloch, A.I.T., Possingham, H.P., Joseph, L.N., Szabo, J., Martin, T.G., 2013. Realising the full potential of citizen science monitoring programs. Biol. Conserv. 165, 128-138. https://doi.org/10.1016/j.biocon.2013.05.025.

Tweddle, J.C., Robinson, L.D., Pocock, M.J.O., Roy, H.E., 2012. Guide to Citizen Science: Developing, Implementing and Evaluating Citizen Science to Study Biodiversity and the Environment in the UK. NERC/Centre for Ecology \& Hydrology.

van der Velde, T., Milton, D.A., Lawson, T.J., Wilcox, C., Lansdell, M., Davis, G., Perkins, G., Hardesty, B.D., 2017. Comparison of marine debris data collected by researchers and citizen scientists: is citizen science data worth the effort? Biol. Conserv. 208, 127-138. https://doi.org/10.1016/j.biocon.2016.05.025.

Vegter, A.C., Barletta, M., Beck, C., Borrero, J., Burton, H., Campbell, M.L., Costa, M.F., Eriksen, M., Eriksson, C., Estrades, A., Gilardi, K.V.K., Hardesty, B.D., Ivar do Sul, J.A., Lavers, J.L., Lazar, B., Lebreton, L., Nichols, W.J., Ribic, C.A., Ryan, P.G., Schuyler, Q.A., Smith, S.D.A., Takada, H., Townsend, K.A., Wabnitz, C.C.C., Wilcox, C., Young, L.C., Hamann, M., 2014. Global research priorities to mitigate plastic pollution impacts on marine wildlife. Endanger. Species Res. 25, 225-247. https:// doi.org/10.3354/esr00623.

Wang, Y., Kaplan, N., Newman, G., Scarpino, R., 2015. CitSci.org: a new model for managing, documenting, and sharing citizen science data. PLoS Biol. 13, 1-5. https:// doi.org/10.1371/journal.pbio.1002280.

Wehn, U., Evers, J., 2014. Citizen observatories of water: social innovation via eParticipation. In: Proceedings of the 2014 Conference ICT for Sustainability, https:// doi.org/10.2991/ict4s-14.2014.1.

Zettler, E.R., Takada, H., Monteleone, B., Mallos, N., Eriksen, M., Amaral-Zettler, L.A., 2017. Incorporating citizen science to study plastics in the environment. Anal. Methods 9, 1392-1403. https://doi.org/10.1039/c6ay02716d. 